\title{
Research on the phenomenon of explosive gas occurrence in drills for an engineering building- Case study -
}

\author{
Cristian Tomescu, ${ }^{1, *}$, Doru Cioclea ${ }^{1}$, Emeric Chiuzan ${ }^{1}$, Adrian Matei ${ }^{1}$, and Răzvan \\ Dragoescu $^{1}$ \\ ${ }^{1}$ National Institute for Research and Development in Mine Safety and Protection to Explosion - \\ INSEMEX, 32-34 G-ral Vasile Milea Street, Postcode: 332047, Petroşani, Hunedoara County, \\ Romania
}

\begin{abstract}
The security status indicator in a work system is characterized by safety levels or by risk levels. One of the types of risks in the workplace is the risk of explosion that is part of the risk factors specific to the working environment - chemical risk factors. The works of consolidating and arranging the infrastructure of a motorway include in their scheme the execution of a series of vertical geotechnical drills of the rock stratigraphic column on which is placed the construction and drillings dimensioned at certain depths and diameters which are concreted in order to ensure the load of the upper structure of the building. In some of these drills there has been a phenomenon of occurrence of gases that, within certain concentration limits, are explosive and create a state of danger by producing an explosion inside them, which by propagating to the surface can affect the safety of workers and means for work. This paper is a case study at a workplace of a trading company specializing in construction and proposes an analysis of the causes of explosive gases occurrence, work environment monitoring, and solutions for diminishing the OHS risk factors.
\end{abstract}

\section{Introduction}

The construction of a highway is an assembly of public utility works, considered to be a special engineering construction of a terrestrial communication category (national roads with bridges, tunnels), with the highest level of traffic separation being reserved only for the traffic and having geometric elements that allow for high flow rates and speeds, in safe conditions.

During the construction of an extra-urban highway in the Transylvania area, near the Mureș River, when drilling for equipping the abutment and piles (reinforced concrete supports ensuring the upper structure of the highway) at a depth of $34 \mathrm{~m}$, occurred a gas explosion inside of a borehole when the bore reinforcement operation was happening.

\footnotetext{
* Corresponding author: cristian.tomescu@insemex.ro
} 
The event did not result in casualties, but the incident highlighted the fact that there are expelling gases in the work area that forms an explosive atmosphere and, implicitly, a state of danger.

In order to identify areas with explosion hazards as well as to protect the personnel, ways of prognostication were sought on the basis of continuous or discontinuous monitoring of the working atmosphere $[1,2,6]$.

\section{Assumptions of the occurrence of gas emissions}

As a result of this incident, the issue of this gas origin has been raised, assimilated to methane, since measurements made with portable gas analysers showed gas emissions with explosive limits between $\mathrm{CH}_{4}=5-15 \%$ vol.

From geomorphological and hydrological point of view, we are in the Mureș meadow, the area is characterized by a collinear-hill relief with intermittent hills interrupted by alluvial plains with the altitude between $300 \mathrm{~m}$ and $500 \mathrm{~m}$. The work platform is located at about $6 \mathrm{~m}$ by the riverbed.

A first hypothesis would be the gas formed in the gullies of a possible riverbed moved in time. In the drilling made near, the stratigraphic column consisted of sedimentary rocks, alluvial accumulation, marl, and sands containing many carbonated plants remains. If we look at literature about the discovery of methane gas, Italian physicist Alessandro Volta discovered methane at the end of the eighteenth century in the gullies of a lake [7].

A second hypothesis may be the presence of frequent gas fields in the Transylvanian Depression, a gas-pressure formation with a certain pressure, from which gases migrate, on the lines of minimum crack resistance in the underground due to the influence of the lithostatic pressure and the temperature of the earth's crust, in areas with lower pressure [2$3,5]$.

A third hypothesis would be the formation of gases in the coal shale formations. In the drilling, there was noticed the presence of a coarse limestone slag of 0.4-0.7 $\mathrm{m}$ in the marlin and sands layer at a depth of about $25 \mathrm{~m}$ from the working platform [5].

Regardless of these assumptions, the existence of methane gas creates a potential explosion risk. The methane gas storage areas are vertically executed drilling and excavation work. These areas are ineffectually ventilated by natural ventilation.

At the level of the industrial sites including at the level of the site under consideration, a series of electric, mechanical, pneumatic or hydraulic machinery or welding machines are used, capable of producing sparks with sufficient energy to initiate an explosive mixture.

Or there may be workers who, unconsciously, over the appearance of gas, may use smoking requisites, which are another effective source of initiation.

\section{Risk analysis given by the presence of gas}

On working platforms or site enclosures, different types of gases may appear constantly or inadvertently.

From the point of view of the effect on the organism can be gases: toxic (carbon dioxide, sulphur dioxide, hydrogen sulphide, nitrogen oxides), asphyxiants (methane, carbon dioxide, various types of hydrocarbons, nitrogen) different types of hydrocarbons, carbon dioxide, hydrogen), radioactive (radon, thoron) [3].

From the point of view of the existing risks for workers, there may be: risk of intoxication, risk of asphyxiation, explosion risk, irritation risk.

As a conclusion from the analysis of the risks from direct and laboratory analysis of flammable gases, the explosion risk existing on the analysed site is representative. 


\section{Prezentation of the results}

From the technical report on the assessment of the gas release phenomenon on the highway alignment in the crossing area of the Mureș River, the following results were obtained [2, 6]:

- During the execution of the foundation at the bridge over the Mures River, at the moment of casting the concrete in a column drilled to a depth of about $30 \mathrm{~m}$, have occurred gas spills;

- The results of direct open measurements have revealed concentrations of flammable gases between 0 and $9 \%$ vol.;

- The results of the direct measurements in closed mode revealed maximum concentrations of flammable gases between 35 and $37 \%$ vol.;

- Following gas chromatographic determinations carried out on samples of gases taken from the analysed area, the following gas concentrations were obtained:

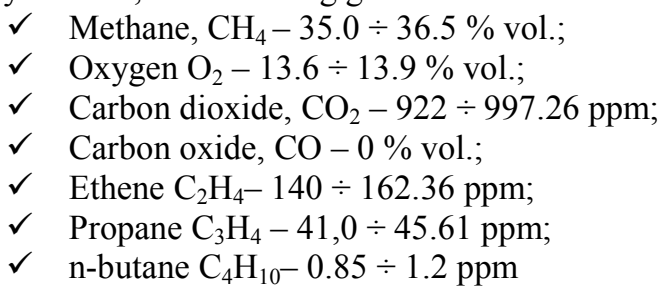

\section{Interpreting of the results}

Of the input data obtained from the measurements and application methodologies the results were interpreted as follows:

- The gradient of increasing the concentration of flammable gases is $\Delta \mathrm{C}=0.65 \% \mathrm{vol} / \mathrm{min}$;

- The relative release of flammable gases was $346.171 / 20 \mathrm{~min}$.;

- The gradient of flammable gas flow was $\Delta \mathrm{Q}=17.311 / \mathrm{min}$ (knowing the free volume of the column, in the upper part, about $2.65 \mathrm{~m}^{3}$ );

- From the analysis of chromatographic gas concentrations, the gas with the highest risk is methane. The other gases identified have low concentrations at ppm, therefore do not pose a risk to workers.

\section{Organizational and technical measures to reduce risk}

For the safe development of the specific activities for the construction of the structures at the level and below the ground level in areas with danger of formation of the explosive atmospheres generated by the upward migration of methane on the alignment of the drilling and the concrete columns it was necessary to ensure the organization of the monitoring activity gas concentrations with portable devices, duplicated by visual observations, and rapid adjustment of prevention measures to local conditions.

The monitoring system was applied differently to the explosion hazard amplitude as follows: borehole monitoring and tracking of abutement and piles.

In addition to the organizational measures, a series of technical security measures have been taken to ensure the safety of the working environment and the working personnel by establishing the ventilation system, the relative methane flow measurements, the air flow rates required for methane dilution or the flow rate the maximum specificity that can be safely ventilated at the level of the drilling, abutement and piles. 


\subsection{Monitoring of Drills, Abutement and Piles}

The monitoring operation during the execution of the vertical drilling (Figure 1) of $1.5 \mathrm{~m}$ in diameter and which are concreted and shuttered in order to provide the load for the upper structure of the highway, was made according to the stage of their execution, that is, intensive daily monitoring with normal, medium and high cadence of the potentially explosive atmosphere, by determining methane and other gas concentrations by means of portable devices during the entire drilling period [2].

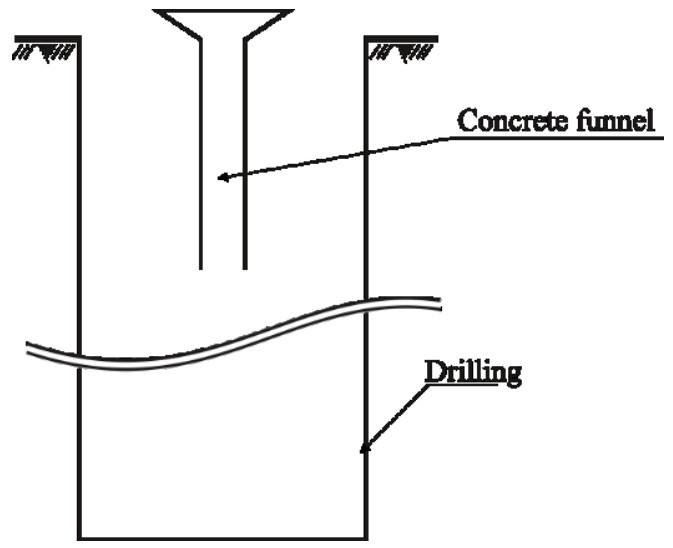

Fig.1. Drilling draw

The monitoring operation during the execution of the abutments / piles was performed according to the stage of their execution, is daily intensive or weekly / monthly monitoring under normal conditions of the potentially explosive atmosphere, by determining the concentrations of methane and other gases, with portable devices, throughout the excavation of the abutments / piles.

Large-sized $(25 / 15 \mathrm{~m}$ or $25 / 10 \mathrm{~m})$ abutments and piles are structures that have the purpose of rigidizing all concreted columns (up to 24 columns per cage and 16 columns per pile) in order to provide the load for the upper structure of the motorway Fig. 2.
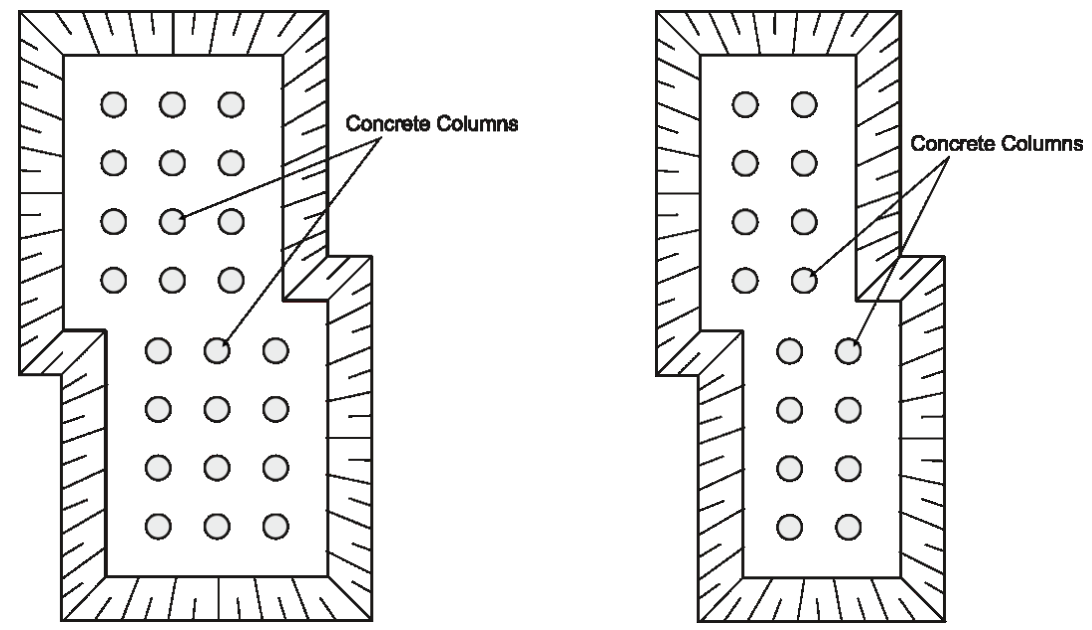

Fig. 2. Abutment and piles 


\subsection{Technical security measures and recommendations in the execution of drilling, abutments and piles}

The main measure to prevent the risk of explosion is to provide adequate ventilation provided by the ventilation system (ventilator and tubing) which provides the oxygen concentration necessary for existing personnel, dilution and evacuation of explosive / toxic substances evacuation of heat and humidity resulting from industrial activities.

In order to fundamentally and efficiently dimension the ventilation method at the level of the three structures, specific parameters were determined $[1,2,4]$ :

a) Determination of relative methane flow at the level of the drilling, abutments and piles;

b) Determining the air flow required for methane dilution;

c) Establishing the ventilation system;

d) Checking the ventilation system;

e) Determining the maximum specific flow rate that can be ventilated safely.

In addition to the above security measures, additional measures to prevent ignition or explosion caused by the presence of flammable gases are required, namely $[2,6]$ :

- Monitoring of flammable gas concentrations by means of portable multi gas devices at the top of the boreholes, abutments piles/ and around them over a radius of $5 \mathrm{~m}$;

- Avoiding the use of open flame near the drilling column, including smoking supplies within a radius of at least $10 \mathrm{~m}$;

- Avoid welding, grinding, metallic metal blows on metal, etc. in the free section of the drilling, abutments / piles or at the top of them;

- Avoiding the penetration of incandescent particles (welding, flexing, etc.) into the free section of the drilling, abutments and piles;

- Avoiding the accumulation of electrostatic charges in the area of drilling, abutments/piles (adequate personal protective equipment, antistatic hose).

\section{Conclusions}

The occurrence of gas explosion in specific infrastructure works (drilling, abutments and piles) of the construction of an extra-urban motorway in Transylvania created a potential explosion risk that generated a dangerous situation in the activity.

The accumulation of explosive gas in a drilling 1,5 $\mathrm{m}$ in diameter and a depth of $34 \mathrm{~m}$, insufficiently ventilated and mixed with air in the presence of an efficient source (spark from the welding operation) produced an explosion in the inside of the drilling that has spread to the surface.

The presence of gas fields or sedimentary formations in which carbonated plant and vegetation remains in the alluvial area of the Mureș River is the most likely source of gas migration in infrastructure engineering works.

The risk analysis of the occurrence of gases in the three structures (drillings, abutments and piles) was performed on the basis of direct measurements of gas concentrations as well as by indirect measurements by gas chromatograph. The risk of explosion is most representative.

In order to reduce the risk of explosion and increase the safety and health of workers in the drilling platform, a series of organizational and technical measures were applied, these are: a gas concentration monitoring system with portable analysers, an efficient ventilation dimensioned according to the relative methane flow as well was applied and additional measures to avoid possible sources of sparks or open flame. 


\section{References}

1. G. Băbuț, I. Matei, Models and methods of forecasting methane emissions (INID București, 1995)

2. D. Cioclea, C. Tomescu, et all., Establish the risks and measures required to conduct business in security during the execution of works on the Transylvania motorway alignment, Mureș County", Contract 5797/02.05.2018, INCD-INSEMEX Petroșani.

3. C. Lupu, C. Tomescu, et all., Coal Exploitation in a Mechanized Coal Face in the Condition of Unexpected occurrence of Methane - case study at Livezeni Mine - Romania - International Symposium "Safety and Health at Work"- 5th Edition, (Sinaia-Romania, 2011)

4. M. Prodan, C. Tomescu, et all., Determination of explosive parameters specific to air-flammable mixtures, under pre-established initial conditions, for the purpose of explosive event, INSEMEX Study 2012 PN 07-45-03-10.

5. C. Tomescu, Research on increasing security in the recovery and enhancement methane in the carboniferous area of the Jiu Valley, The Thesis Doctorate, University of Petrosani.

6. C. Tomescu, A. Matei, et all., Measurements made in the field on the motorway Transilvania, Monthly Technical Reports (May-June 2018), INCD-INSEMEX Petrosani.

7. Al. Volta, Lettere del Signor Don Alessandro Volta ... Sull' Aria Inflammabile Nativa delle Paludi [Letters of Signor Don Alessandro Volta ... on the flammable native air of the marshes], Milan, Italy: Giuseppe Marelli (1777) 